\title{
Boundaries of Logics in Municipality Communicators' Facebook Practice: Towards a New Public Service Competence
}

\author{
Livia Norström \\ School of Business, Economics and \\ IT, University West, Sweden \\ livia.norstrom@hv.se
}

\author{
Iréne Bernhard \\ School of Business, Economics and \\ IT, University West, Sweden \\ irene.bernhard@hv.se
}

\author{
Ulrika Lundh Snis \\ School of Business, Economics and \\ IT, University West, Sweden \\ ulrika.snis@hv.se
}

\begin{abstract}
With an increased use of external online platforms, digital government logics are gradually intertwined with external, algorithmic, crowd-influenced value logics of social media platforms. This new scene especially affects administration, which can no longer neutrally deliver public service, but becomes involved in processes of consideration and judging what rules and traditions seem most appropriate in the situation. Through deep interviews and workshops with municipal communicators, we examine this balancing act when communicators use social media for external communication. We use a practice perspective to characterize and conceptualize an emerging approach to public service.
\end{abstract}

Keywords: Public Service, Social Media Platforms, Digital Government, Public Administration, Communicators, Value Logics, Practice Perspective

\section{Introduction}

Digital government practices founded in familiar rational service delivery are increasingly complemented by networking initiatives and ideas of responsiveness and co-creation [1-5]. The new practices expand and blur the boundaries of the organization [6-8], challenge established interactions and relations with citizens [8,9], and shape public administrators' standpoints and activities regarding government's mission [4, 10]. Communicators in public administration are a group of administrators particularly affected by this change $[5,11,12]$. Due to the current pervasiveness of social media in government and in society, the role of government communicators increasingly involves being the main gatekeepers of citizens' contact with the government, and to uphold a promotional "shop window" to the surrounding society. These diverse roles imply a balancing act between different approaches to digital government's mission (e.g. transparency, dialogue and collaboration) $[10,13]$ and to traditions and ideological value logics constituted by the government [4, 5]. Government approaches to public service have, according to Bryson [5], shifted historically from a traditional approach where public service is a means for upholding laws and equity, into new public management, a marketing-oriented perspective in which efficiency and serving citizens as customers is emphasized, to an emerging approach where technology has an important role with networking and democratic action as important ingredients.

With an increased use of external online platforms, the institutional logics of digital government are intertwined with external, algorithmic, crowdinfluenced value logics of social media platforms [14]. The business concept of social media platforms, e.g. Facebook, is to create a predictive product that can foresee users' future needs. To do so the platforms are designed to make people share personal and interactional data online, which they can collect and analyze in order to create even more efficient algorithms [8, 15]. The technological architecture of social media platforms gives rise to a huge generativity of resources such as skills, knowledge and connections that again can be reproduced and diffused [16]. The pervasiveness of online service such as social media can be explained by the relatively easy-to-use, lowprice technology that lowers the barrier to advanced technological functions and as such enables not only big firms but individuals and small organization to take part in exchange processes of ideas and new knowledge $[17,18]$. In that way social media platforms and their related service potentially tie people with the same interests together, and enable them to create content and share views and ideas together in a shared space $[19,20]$. This stimulates government to use social media to improve public service by communicating with previously unreached groups of citizens, and gives citizens the chance to effortlessly 
get in touch with the government for various purposes $[10,21,22]$.

Due to increased citizen participation and the influence of online platforms in public service work, the role of administrators has become more dynamic and more value loaded. Public administration has transformed from a neutral, technically oriented expert institution into an administration that embeds value into its activities [23]. Public administration earlier had an advisory role to politics and as such has historically been detached from direct democratic processes such as voting and decision making. With a new emerging approach in which a close and trustful relationship to citizens has become increasingly important, public administration faces new challenges related to a professional practice of judging what services citizens value most and how they should be performed [24]. A new approach for public service is thus emerging in which bureaucracy and efficiency still persist but where networking, relationships and democracy have greater impact [5]. Work practices in the new approach are less structured by predefined procedure. Instead they are negotiable and idealized. Broadly, administrators need to switch between different approaches to traditions and value logics in their social media practice. This balancing act means being accountable, responsive and lawful bureaucrats, and simultaneously acting as personal, promoting and efficient partners $[4,25]$. The practice of the communicators is typically characterized by tensions between what is possible to do with social media platform logic in relation to the mission of the government and to citizens' wishes, and what is allowable within the frames of digital government logics $[4,11,25]$. As a consequence, there is a lack of established working procedures that individual workers and public agencies can adapt to [13]. The relationship to citizens is especially important at a local government (municipal) level where public service is related to citizens' everyday living (e.g. housing, communications, education, healthcare, etc.) and which thus has potential to engage citizens to participate [26].

From these perspectives we conceptualize the work of municipal communicators as emerging practices where value logics at different levels and from both within and outside the municipality are entangled. The purpose of the study is to explore how digital government logics and social media platform logics are intertwined in government communicators' social media practice and more specifically why and how standpoints, approaches and activities emerge and are transformed in practice, when social media is used for public service. The research question is: How are different value logics realized in the social media practice of municipal communicators? The emerging approach of public administration is important to understand not only because it may shed light on how public service can be efficiently delivered but also because service in this government is co-created with citizens in democratic processes. Bryson [5] and Lusch and Nambisan [6] call for more research on how processes of co-creation are enacted in service processes and how the role of IT influences these processes. We are not searching for a final answer where value logics are in consensus. Instead we aim to illustrate processes of public service in which value logics at different levels are sometimes contradictory while still highly interdependent and intertwined [25].

\section{Contextualizing public service}

Public institutions uphold cultural values and norms that give them authority and set the context for social interaction and for how public service is chosen, created and delivered [5, 27]. Additionally, when external, online services (e.g. Facebook) are used for public service, these become another equally important agent shaping the practice of the online service users $[14,28]$. In this section we outline a spectra of logics on different levels, from institutional and ideological logics, to technical algorithmic business rationalities, that are all involved in digital government public service work, and in this study specifically in the social media practice of municipal communicators.

\subsection{Notions of service}

All enterprises, public organizations included, need a mental model or institutional logic to function [6]. Although manufacturing (production and exchange of goods) is still important in today's business paradigm, the Internet and associated innovations are part of an emerging institutional logic based on "service" [29]. In this perspective the definition of service is "the application of specialized competences (knowledge and skills) through deeds, processes, and performances for the benefit of another entity or the entity itself' [29] (p. 2). Service is global and works across cultural and geographical boundaries, influencing different service worlds to engage [6]. Interaction and relations between the service worlds are therefore increasingly important in order to understand the efficiency and quality of service [6]. Service platforms such as social media are an important aspect of service not only for enabling scale, scope and reach of resources (skills and knowledge) $[16,30]$ but also because they are an important part of the shaping of the design, delivery and influence of service $[14,31]$.

The question of how technology shapes organizations has been extensively studied within information 
systems (cf. [32-34]). One of the most influential theories on this topic is the "practice perspective" [35] in which technology is not understood as coming with a set of inscribed structures for users to appropriate. A practice perspective instead implies "emergent technology structures enacted in practice" [36], i.e., structures such as experience, knowledge, meaning, habits, power relations and norms are not fixed in the technology but rather emerge in the use of technology. Using a practice lens "directs attention to how institutional phenomena are constituted in everyday activities, and how those everyday activities, in turn, are shaped by institutional influences and entailments" [14]. Using a practice lens means to direct the focus of analyses to recurrent situated activities, in which some meaning is shared among actors [37]. Looking into everyday practices for understanding service is argued to be fruitful in order to understand how resources and relationship are reconfigured in processes of value creation $[14,29,38]$.

\subsection{Digital government logic}

This value logic describes the mission of the digitalized municipality and the relationship between government and citizens by means of information technology.

"Public service relates to service in public sector with the purpose to generate value to the public" [27] (p. 211). It refers to the management of government administrative tasks that are key to the government's core activities (e.g. police, education, healthcare, housing, environment and communications) [39]. Public service is for example information, guidance, counselling and certain government exercises, in any type of office and more often through technologysupported service channels [40].

The approach to service in the public sector has historically shifted from a government-centred view via new public management to a new and emergent network-centric approach [5]. In the governmentcentred approach administrators are civil servants who are supposed to provide service to citizens in order to uphold legality and equity. They follow bureaucratic procedures based on laws and regulations rather than focusing on customer satisfaction or citizens' input. Success of public service in this view is measured in terms of adherence to legal processes. In this approach citizens have a passive role $[5,41]$. This bureaucratic view was challenged by a new public management approach, adapted from the private sector where focus is on customer satisfaction. Here legal procedures are de-emphasized and the attention is focused towards efficiency and market-driven service. Citizens are viewed as customers and consumers of service who should be satisfied by government. The third and emergent approach has a network-centric focus. In the two earlier approaches democratic processes were thought of as restricted to elections and legislative deliberation. In the emergent approach the development goes towards more active citizenship where administration aims to create dialogue and act in response to citizens' wishes in order to improve service and welfare and ultimately increase the public good [5]. The emergent approach has had an increased boost in the past decade due to Internet, affordable technology and the pervasive use of online service. Even though the emphasis on the different approaches has varied at different times, aspects of all approaches co-exist [5], which gives rise to tensions between practices of how service can and should be delivered. When tensions between different approaches are enacted in practice, the question of who benefits from public service is at stake. The concept of "impartiality" is the exercise of public authority and a core concept of quality of government [42].

Despite the pervasiveness of social media in government agencies, interaction level is relatively low compared to the interaction level on the same platforms used by private organizations [9, 27, 43]. Part of the "failure" of not being able to take advantage of democratic aspects of networking may be explained by the difficulties for public organizations to adapt to fast change [27]. Due to its bureaucratic character, changing ideas and processes in the public sector are different from innovative ideas and activities in the private sector [27]. Government organization is less autonomous and more affected by political influence, it needs to deliver service regardless of citizens' wishes and it has a non-financial and qualitative interest. One main concern regarding public service is that is has to be universal and accessible to as many people as possible but at the same time unique and adjusted to the context in which it is delivered. Public government also has a high responsibility to administer common resources so as to guarantee quality of life to the citizens [27]. On the one hand the bureaucratic character of public sector institutions may be viewed as an obstacle to innovation, but on the other hand, proper consideration reduces the risk of making wrong decisions and moving in a less fruitful direction, which may guarantee higher quality [27].

\subsection{Social media platform logic}

This value logic describes the business rationale of social media platforms and the commercial and innovative ideas underlying it.

Social media services such as Facebook can be viewed as the underlying dynamic of a large 
infrastructure [16] that enables resources such as knowledge and skills to be generated, diffused and recreated [44]. On the one hand the generativity of resources, widely available, expands and blurs the boundaries of the organization [6-8] and empowers individuals and small organizations to take part in innovation processes $[17,18]$. On the other hand the financial and technical resources needed to uphold such infrastructure are huge, which creates a monopoly of already established Internet industries (e.g. Facebook, Amazon, Apple and Google) that can, undisturbed, create their own standards, rules and regulations without competition [44].

Algorithms are a fundamental building block of social media platforms such as Facebook. "Algorithms are a set of step-by-step instructions to achieve a desired result in a finite number of moves" and "algorithms act, they do things" [14] (p. 18). "Algorithms feed the user with relevant information for the specific context and situation" [14]. They are based on analyses of users' shared data online with the aim to predict future needs and enable and trigger users to share as much data as possible by interacting online [8]. In a TED Talk, O'Neil [45] emphasizes the importance of understanding and acting on the fact that algorithms are not neutral. "Algorithms are opinions embedded in codes... we think algorithms are neutral and scientific but they are a marketing trick... algorithms don't make things fair, they repeat our past practice, our pattern our ultimate status quo" [45]. As such the logic of social media platform providers and their use of the crowd for business purposes must be taken into account to understand how different institutional logics entangle and are enacted in the work with social media [45].

\section{Method}

The study is part of an ongoing collaborative project, started in 2014, between regional municipalities and the university to develop practice of, and research into, social media use in municipalities. In order to get deep knowledge of the municipal communicators' individual perceptions and thoughts about their social media practice, we applied an explorative and qualitative research approach [46, 47]. In particular a case study was conducted in order to "shed light on a contemporary phenomenon (the 'case') in depth and within its real-world context" [46] (p. 16). The purpose was not to compare different municipalities' or individuals' perspectives but rather to get a broad spectrum of different views. The research approach was abductive, i.e., an explorative approach to the empirical findings was alternated with analysis related to existing scholarly research [48].

\subsection{Research context}

The study focuses on the social media practice of municipal communicators in Sweden ${ }^{1}$. The municipality is main provider of public services and the level of government closest to citizens [50]. This aims to relate democracy and public administration to local distinctiveness and the interests and ideas of citizens. The most common social media platform used by municipalities in Sweden is Facebook, as 219 out of 290 municipalities have an active Facebook page managed by the central administration [51].

\subsection{Data collection and analysis}

In this study, two semi-structured deep interviews were conducted (in 2015) followed by two participatory workshops (one in May and one in November 2017) in which altogether nine small and medium-sized municipalities and 23 municipal communicators participated. After the workshop in May, semistructured deep interviews were held with five of the participants. The municipal communicators in the study have overall responsibility for strategic and hands-on external communication in their municipality including managing official social media channels, such as Facebook, LinkedIn, Twitter and Instagram, and the municipal website. Thus the communicators have communication as a profession. The background of the communicators varies: Two of the interviewees have a professional communication background, two are former journalists, one was previously a consultant webmaster in the private sector, and four have extensive background as administrators at different levels in the municipality without a particular specialization in communication.

Both workshops started with a presentation and discussion of the research groups' latest findings, based on previous interviews and workshops where nine of the communicators have participated since 2014, and scholarly research. A main topic throughout the discussions has been tensions between what the communicators believe are proper actions as public servants (e.g. being accountable, transparent, formal, etc.), and what they experience as new opportunities with social media in interaction with citizens (e.g. promotion, informal conversations, being timely and immediate, etc.).

In the first workshop four themes were then discussed in two groups: Purpose and aim of social media use in the municipality; Opportunities and

\footnotetext{
${ }^{1}$ The share of the population in Sweden with access to the Internet at home was $91 \%$ in 2017 . The use of social media platforms has increased in recent years and was $81 \%$ in 2017 , with $74 \%$ of Internet users using Facebook [49].
} 
challenges of use in relation to purpose and aim; Processes of information and knowledge transfer between citizens, administration and politics in social media; and Future thoughts about social media use in the municipality. The second workshop was even more open-ended with two main questions: What are the main lessons learned regarding the work with social media in your municipality?; and What do you want to focus on/learn more about in the future? The first workshop lasted for half a day, the second for one full day. The interviews lasted for 1-1.5 hours and aimed to expand on the discussions in the workshop and therefore focused on the same themes. The interviewees were selected because of their previously demonstrated interest in university collaboration related to social media in public sector. In addition, an analysis of policy documents and work descriptions from the municipalities was conducted.

The workshops and interviews were audio recorded. The interviews and the second workshop were transcribed verbatim, while the first workshop was listened through multiple times while notes were taken from parts of discussion relevant to the research interest in the study. A thematic analysis of interview and workshop transcripts and notes from the first workshop was then conducted. In accordance with the abductive research approach, theory reading was alternated with an explorative empirical analysis. Realization of different value logics became visible through processes of consideration and negotiation in everyday social media practice, described by the communicators.

\section{Findings and analysis}

The findings describe three critical concerns emerging in municipal communicators' social media practice, in which consideration and negotiation of digital government logics and social media platform logic occur, and where new practices are sometimes shaped. These concerns can be summarized by the following themes: To treat citizens equally; to trigger engagement; and to take risks for good reputation and professional acting.

\subsection{To treat citizens equally}

One key principle in a set of different digital government logics is the equal treatment of citizens [42]. This was a principle that typically caused challenges when facing the logic of social media platforms that trigger uniqueness and communicative intimacy. A balancing act across boundaries of logics was ongoing regarding this concern.
The first example illustrates one communicator's thinking and actions when a big running race will be held in town. The communicator knows it is an important event to many people and organizations and a great opportunity to reach out to many citizens on Facebook, but a problem with these big events is that the arranging organization gets too much attention at the expense of smaller organizations. The communicator explains the feeling of being controlled to comply with the laws and at the same time striving to use the benefit of Facebook to reach out to a large audience. "We constantly feel that someone is keeping an eye on us because of the principle of equal treatment. Just because the annual race is great news we cannot promote a single event too much. Even if it's a non-profit organization that gets the money, we have to be a little careful. Instead you can think: our municipality is a music municipality and we contribute live music along the route. As such we've got an angle that is okay, we've talked about the municipality as a swinging municipality and we have promoted our music school and not the race as such. And then later on we tell about the traffic rearrangement in relation to the race, and then we have another angle to the same news." The example shows how attention is focused not so much on the event as such and the organization arranging it, which would had been easily "liked" and "shared" on Facebook, but instead on municipal activities surrounding the event. Hence, to avoid transgression of equal treatment the work with the big event is transformed from pure promotion of organizers into important information and promotion of municipal activities. The communicator typically finds topics that relate to citizens' everyday living, because $\mathrm{s} /$ he knows that those will engage people and make them interact on Facebook, instead of promoting a single event which will generate many likes and shares but has little relevance for the mission of the municipality. There is a balancing act between different government regulations and between digital government logics and social media logics.

The second example of these balancing acts of logics and regulations illustrates a situation when Snapchat is considered as a new social media channel in one municipality. Snapchat is thought of as a proper channel to use to reach out to young people who, according to the communicators, are usually difficult to contact. However, it is avoided because of uncertainty of how the mission of accountability can be upheld when the conversations cannot be retrieved. One communicator says: "Accessibility [of information] is very important because anyone should at any time be able to request information... let's say you talked via Snapchat about something, and someone wants to have that [conversation] now, then you have to be able to 
hand it over and if you can't you are breaking the law. I think for sure that we will join [Snapchat] too, but we are constantly facing channel choices.... I think Snapchat is fantastic and we would absolutely like to use it but right now we are in a situation where we need to dig a bit deeper before we dare." The example illuminates a dynamic in practice between different regulations within the e-government context: accountability and equal treatment. While the purpose of using new channels such as Snapchat is to reach out to young people, in practice this purpose is difficult to fulfill. On the one hand, matters related to the exercise of public authority have to be accessible by the public and the transitory nature of Snapchat cannot guarantee such accountability. On the other hand, if young people are not reached, the municipality has a problem with lack of inclusion and equal treatment. If one regulation is violated, the other can be adopted, but the two are difficult to reconcile.

\subsection{To trigger engagement}

A second issue that typically gave rise to consideration of different logics was related to the municipality's relation to the citizens in terms of what approach and tone is efficient in order to foster a good relationship with citizens and at the same time uphold a serious impression as a government. While social media platforms afford a personal, easy-going tone that matches well with a service, promotional and businessoriented relationship to citizens, as emphasized in the new public management approach, the municipality also has a long tradition of responsibility and bureaucracy that is mirrored in the relationship to the citizens as formal and distant. A balancing act between different digital government approaches and social media logic was discussed.

One communicator finds it important that the municipal Facebook page has an informal and friendly tone, that it is frequently updated, and that answers are given promptly. S/he is used to working $24 / 7$ and on weekends and has no problem being constantly available for citizens on Facebook. S/he says: "Social media is just as it sounds like being a friend... The municipality should be a friend of the person who 'likes' us. When you see a message from us, you should know that either it is interesting or it is something you did not know. Or something funny." The same communicator emphasizes the importance of a mutual responsibility of citizens and municipality and continues to compare the relationship to a friendship, where both sides have to contribute. $\mathrm{S} / \mathrm{he}$ is also convinced that it's up to citizens to understand how social media works and that it is not the role of the municipality to convince citizens to study municipal information: "Every time you press 'like' on a post [on Facebook], you will see the next post too, but if you never press 'like,' the municipality posts will disappear from your feed even if you like it, that's what it's like, that's how Facebook works... If you don't understand that I think you have yourself to blame. It can't be my task to tell them [citizens] how Facebook works, that's something they have to understand themselves. Social media is about interaction, it's not just me who should offer things, they should actually give me something too, they should give me a hint, a comment, a press on a button. And if they don't, they're probably not very interested."

Another communicator takes a slightly different approach. $\mathrm{S} /$ he is more deliberate and careful about only posting high-quality material, about things going on in the municipality that benefit the citizens, she gets stimulated by helping citizens and $\mathrm{s} / \mathrm{he}$ is restrictive about promotional posts such as beautiful pictures from the municipality, even though s/he knows they will generate "likes" on Facebook. S/he says: "Of course we want engagement and all, but it should still be quality and benefit the citizens, the information we provide... so we are also a little selective, we don't want to put out too many just crazy pictures without any real content.... And then you receive quite a lot of questions as private messages. And if I feel I can help out so easily even though I'm not at the office, like read about it here, they [the citizens] get very happy and then I feel, aha, I could help that person very easily."

In these empirical examples we see that there is a spectrum of different ideas of how to approach citizens and how to trigger engagement in social media. The first example shows the importance of treating citizens as friends but at the same time as individuals with their own responsibility to learn social media techniques and benefit from interaction with the municipality. The second example illustrates a more caring approach characterized by strong responsibility for the citizens and the reputation of the municipality. In the first example the communicator transgresses principles of inclusion by expecting citizens to know how to use Facebook to maximize the benefits of use. The focus is instead on narrowing the distance to the citizens through creation of interesting, relevant content and a friendly tone. S/he strictly follows the social media sharing logic and transforms work accordingly. In the second example we see an approach characterized by trying to uphold traditional digital government logics and partly neglecting social media logics by refraining from the temptation to post what s/he knows will get lots of Facebook attention but that does not naturally provide necessary knowledge. At the same time s/he takes advantage of social media logics of sharing and 
reconstruction of resources in practice by adjusting the practice and answering questions outside office hours.

\subsection{To take risks for good reputation and professional acting}

The third issue is related to the potential risk the communicators are prepared to take in terms of losing control of their professionalism and the reputation of the municipality due to their social media performance.

One communicator describes the circumstances under which they work as very insecure. S/he says that social media has many potential benefits but, due to its unpredictability, it is also risky and scary. The communicators have to be prepared to handle lots of negative comments. The fast and immense spread of Facebook posts and citizens' comments easily risks putting the communicators in an uncontrollable situation and ultimately risks generating a negative reputation of the municipality. One communicator says: "It's a great tool if you can handle it and not everyone can. It's like a two-headed monster. It's terrifying in a way... There are municipalities that have really put their foot in their mouth, such as in a neighboring municipality where the residents of a retirement home didn't get their New Year's Eve dinner. It became a mess. It's not funny to end up in such a shit storm. In those situations you really have to hang on to your hat because otherwise you can easily lose control over your Facebook feed. And that's what happened. They lost control."

Another communicator sheds light on the difficult task of both having a friendly and easygoing tone on Facebook and simultaneously representing an authority. "How much personal tone can possibly be tolerated without simultaneously renouncing our authority? We constantly collide with the fact that we are bureaucrats basically; we must be righteous and trustworthy and comply with the laws. And then we start hesitating when we throw in stuff like look how cozy we have it here, how nice, and then we poke a little bit on the trust that is so vital... But actually, I don't think there is any contradiction... but it's new and unknown and uncomfortable to many of our officials, myself included. I have worked a lot in the public sector, how much can we stretch the boundaries here without damaging our credibility?"

Another communicator says: "It's pretty much about culture. What space do we have in the municipality to arouse passion and play on people's feelings... when we simultaneously have a social obligation to protect children's wellbeing, which sometimes involves police interventions and other means of authority? And then at the same time we're supposed to sit here and talk about how compassionate we are and how much we care. I find it very difficult. What are we supposed to do... what's a reasonable code of conduct here?"

One communicator has observed that to get a spread of posts on Facebook today you have to have your audience share and comment on the post. S/he says s/he struggles to create dialogue with citizens but there is always time pressure that restricts the efforts. "When you sit there in the middle of everyday work you don't really want dialogue. Sometimes you even avoid posting things that create dialogue even though dialogue is exactly what we want." The communicator pinpoints the fact that using Facebook as a one-way promotional channel is not as difficult and time consuming as actually triggering and upholding engagement.

The examples illustrate a shift from an informative and bureaucratic role of the communicators situated within clear organizational boundaries into a role as a promoting, constantly available service deliverer, or "friend" that is always there for the citizens and that needs to take risks to damage trust in order to uphold trust. The new role clearly requires more resources in time and engagement and a higher level of risk-taking which are not always accounted for by municipal management.

\section{Discussion}

The increased use of social media for municipal communicators leads to challenges with how to perform public service and in doing so how to act competently in increasingly complex dynamics of different boundaries of logics. In order to understand social media use in municipalities, in this paper we used a practice perspective to see how different government logics and social media platform logics were realized. Using a practice lens to study technology in organizations implies a belief that norms and values do not exist as inscribed in structures for users to adopt, but rather that they exist only in the situated practice of the technology [36].

The scene is set to be viewed as a constantly negotiated practice with lots of experimentation. Resources are available such as previous knowledge and skills from digital government value logics [5] that become truly intertwined with technology in-situ logics $[8,44]$, i.e., the platform logic. This boundary work is under continuous becoming and the communicators' experimentations are a result of how they perform public service based on their application of their specialized knowledge and skills. The dynamic relationship between the practice of boundary logics and its technology-related experiences becomes the scene for a "new" workspace where traditions, rules 
and regulations are intertwined with new networkinfluenced platform rationalities. What we see here can be conceptualized as an emerging approach to public service that implies a dualism divided into greater possibilities for increased online democratic conversations on the one hand, and conditions for what a municipality "should do" on the other [4].

Due to its bureaucratic character, changing ideas and processes in the public sector are different from innovative ideas and activities in the private sector [27]. While private sector can without problem target certain customer groups, the communicators in public sector have to constantly consider how service can benefit all and how they can uphold a trustworthy image while at the same time talking to the citizens in an informal, inviting tone to create engagement. This can be problematic in practice since social media platform logic builds on generativity of information and resources and a sharing culture in which people voluntarily engage with other people and information. And to trigger a voluntary engagement, user experience is of main importance as well as a contextual understanding and relevance of the stuff engaged with. The communicators in the study, who have communication as a profession, are aware of this dilemma and they constantly tune their work in social media to fit both a more general public and to touch individual citizens to engage.

In this act of balancing between different government logics and social media platform logics new work practices emerge. Both the government centered approaches and the new public management approaches are well known strategies that the communicators feel comfortable with. However, when social media platform logics increasingly govern their work, hesitation occurs. Upholding a constant dialogue with citizens requires citizens to trust the communicators and the government and to gain trust the communicators need to have their work legitimized. We argue that the balancing act between the different logics is a process of legitimation and a process of learning to become more competent as a communicator when service platforms enter the scene of public service in general, and municipality communication in particular.

As we have shown in the study, this work is experienced as risky. If social media is going to be used, it has to be taken seriously since the effect of what approach taken can have fatal consequences. As for instance in the example of one communicator's neighboring colleague who had a history of only pushing promotional material to the users, without having a substantial dialogue, and then he/she made a mistake, and "ended up in a shit storm". Social media logics do not take a political or personal stand, they only perform in relation to quantitatively measured behaviors of the crowd $[8,14]$. If a communicator has a low level of interaction on their Facebook page (as was the case for the neighboring colleague), and suddenly people start reacting to something negative, that negativity will spread widely. Algorithms repeat patterns in the past $[14,45]$ which means that such negative scenarios will be difficult to stop or change.

Acting professionally in social media i.e. to take advantage of social media platform logics and balance them with government logics takes time and consideration, which is not always taken seriously by the municipal organization. Participants in the study report on time pressure and insecurity as resources and organizational adjustment to the extra efforts required when using social media is limited. However the communicators sophisticated reflections in the study indicate a growing maturity and that a new competence is on its way among communicators alongside an increased use of different algorithmic and crowd-based service platforms.

We argue that a new approach to public service implies taking a stronger service perspective [29], working with closer relationships and finding clusters of resources (skills and knowledge) that are unique to that cluster and talking specifically to them [6]. Talking to small groups about issues related specifically to the citizens in those groups is one strategy that may support communicators to be empowered enough to develop legitimacy to make individual citizen act. It is also important to have the "right" individual citizens connected to certain skills and knowledge, i.e., individuals or groups of citizens who are influential in the specific network and who in turn have legitimacy to make citizens further act so that network effects will be enhanced. Hence, relevant knowledge and skills are not enough; the $i$ engaged in these recourses, as well as the communicator in the role of facilitator, all have to be legitimate to trigger engagement.

In summary, based on scholarly literature and our empirical findings we suggest a reconceptualization of (digital) public service that has a stronger focus on service as processes of shared and recreated knowledge and skills for all actors involved in the process [6], and that more clearly takes into account both technological value logics and institutional value logics as they are being realized in practice.

\section{Conclusion and further research}

We have shown how different institutional logics are upheld and reconfigured from more or less strict digital government structures to a socio-technical assemblage of intertwined government and social media platform 
logics. In that process municipal communicators' role is to judge what approach is most suitable in relation to traditions in the municipality. There is no final point when logics are in consensus because social media platforms are in a constant dynamic of algorithmic performance and activities of the crowd. Instead, to professionally provide public service with social media, communicators need to partake in an ongoing (and improved) socio-technical practice [25]. In the paper we contribute with characteristics of such public service provision and suggest a reconceptualization of public service adapted to the influence of social media platforms.

The dynamics of how logics are realized is complex and needs to be further examined. This is important not only for researchers in order to theorize social media practice in a municipality, but also for managerial purposes in municipalities so that social media can be better anchored in the organization and provide the practitioners with the right support and resources to develop their work.

Within information systems there is a tendency to believe automation of professions will be more efficient and of higher quality. This study indicates that individual human judgment and social competence is important. The value of service is constructed in the social interaction between municipality and citizens with the communicators as main facilitators. The role of the communicators is value loaded. Automating the relationship between municipality and citizens risks giving too much agency to social media platform providers and algorithmic logic. An uncritically automated development of public service may lead to upholding inequalities and other problems that governments aim to improve since algorithms repeat existing structures. More research on agency of different actors (both technological and human) in public service provision is therefore of importance in order to better understand how public service can be a more efficient tool for democracy. Besides, a more structured identification and categorization of different value logics and specific co-creation process of values within social media practice in municipalities is a topic for further research.

\section{References}

[1] D. Linders, "From e-government to we-government: Defining a typology for citizen coproduction in the age of social media," Government Information Quarterly, vol. 29, 2012, pp. 446-454.

[2] I. Mergel, "Building Holistic Evidence for Social Media Impact," Public Administration Review, 2017.

[3] E. Bonsón, S. Royo, and M. Ratkai, "Facebook practices in Western European municipalities: An empirical analysis of activity and citizens' engagement," Administration \& Society, Vol. 49, 2017, pp. 320-347.

[4] M. Bergquist, J. Ljungberg, B. Remneland, and B. Rolandsson, "From e-government to e-governance: Social media and public authorities legitimacy work," 2017.

[5] J. M. Bryson, B. C. Crosby, and L. Bloomberg, "Public value governance: Moving beyond traditional public administration and the new public management," Public Administration Review, vol. 74, 2014, pp. 445-456.

[6] R. F. Lusch and S. Nambisan, "Service innovation: A service-dominant logic perspective," MIS Quarterly, Vol. 39, 2015.

[7] C. Sørensen, "The Curse of the Smart Machine? Digitalisation and the children of the mainframe," Scandinavian Journal of Information Systems, Vol. 28, 2016, pp. 57-68.

[8] S. Zuboff, "Big other: surveillance capitalism and the prospects of an information civilization," Journal of Information Technology, Vol. 30, 2015, pp. 75-89.

[9] R. Medaglia and D. Zhu, "Public deliberation on government-managed social media: A study on Weibo users in China," Government Information Quarterly, 2017.

[10] I. Mergel, "A framework for interpreting social media interactions in the public sector," Government Information Quarterly, vol. 30, 2013, pp. 327-334.

[11] L. Norström and M. Hattinger, "Efforts at the Boundaries: Social Media Use in Swedish Municipalities," in International Conference on Electronic Participation, 2016, pp. 123-137.

[12] P. Simmons, "Challenges for communicators in future Australian local government," Procedia-Social and Behavioral Sciences, Vol. 155, 2014, pp. 312-319.

[13] C. G. Reddick and D. F. Norris, "Social media adoption at the American grass roots: Web 2.0 or 1.5?," Government Information Quarterly, Vol. 30, 2013, pp. 498-507.

[14] W. Orlikowski and S. V. Scott, "The algorithm and the crowd: Considering the materiality of service innovation," 2015.

[15] C. Alaimo, J. Kallinikos, and P. Roth, "Encoding the Everyday: Social data and its media apparatus," Big Data Is Not a Monolith: Policies, Practices, and Problems, Cambridge: The MIT Press, 2015

[16] D. Tilson, K. Lyytinen, and C. Sørensen, "Research commentary-Digital infrastructures: The missing IS research agenda," Information Systems Research, Vol. 21, 2010, pp. 748759 .

[17] H. W. Chesbrough, Open innovation: The new imperative for creating and profiting from technology: Harvard Business Press, 2006.

[18] E. Von Hippel, Democratizing innovation: MIT Press, 2005.

[19] A. M. Kaplan and M. Haenlein, "Users of the world, unite! The challenges and opportunities of Social Media," Business Horizons, Vol. 53, 2010, pp. 59-68.

[20] D. Yates and S. Paquette, "Emergency knowledge management and social media technologies: A case study of the 2010 Haitian earthquake," International Journal of Information Management, Vol. 31, 2011, pp. 6-13. 
[21] T. A. Bryer and S. M. Zavattaro, "Social media and public administration: Theoretical dimensions and introduction to the symposium," Administrative Theory \& Praxis, Vol. 33, 2011, pp. 325-340.

[22] United Nations, "United Nations E-government Survey 2014: E-Government for the Future We Want," 2014.

[23] T. M. Harrison, S. Guerrero, G. B. Burke, M. Cook, A. Cresswell, N. Helbig et al., "Open government and egovernment: Democratic challenges from a public value perspective," Information Polity, Vol. 17, 2012, pp. 83-97.

[24] I. Bernhard, "E-government and e-governance: local implementation of e-government policies in Sweden," KTH Royal Institute of Technology, 2014.

[25] L. Norström, A. S. Islind, and H. Vallo Hult, "Balancing the Social Media Seesaw in Public Sector: A Sociomaterial Perspective," 2017.

[26] K. Mossberger, Y. Wu, and J. Crawford, "Connecting citizens and local governments? Social media and interactivity in major US cities," Government Information Quarterly, Vol. 30, 2013, pp. 351-358.

[27] J. Bertot, E. Estevez, and T. Janowski, "Universal and contextualized public services: Digital public service innovation framework," Government Information Quarterly, 33(2), 2016, pp. 211-222.

[28] W. J. Orlikowski and C. S. Iacono, "Research commentary: Desperately seeking the 'IT' in IT research-A call to theorizing the IT artifact," Information Systems Research, vol. 12, 2001, pp. 121-134.

[29] S. L. Vargo and R. F. Lusch, "Evolving to a new dominant logic for marketing," Journal of Marketing, Vol. 68, 2004, pp. 117

[30] Y. Yoo, "Computing in everyday life: A call for research on experiential computing," MIS Quarterly, 2010, pp. 213-231.

[31] N. C. Ramiller and M. Chiasson, "The service behind the service: sensegiving in the service economy," in Information Technology in the Service Economy: Challenges and Possibilities for the 21st Century, Eds. M. Barrett et al., Springer, 2008, pp. 117-126.

[32] P. M. Leonardi and S. R. Barley, "What's under construction here? Social action, materiality, and power in constructivist studies of technology and organizing," Academy of Management Annals, Vol. 4, 2010, pp. 1-51.

[33] W. J. Orlikowski and J. J. Baroudi, "Studying information technology in organizations: Research approaches and assumptions," Information Systems Research, Vol. 2, 1991, pp. $1-28$

[34] W. J. Orlikowski and D. C. Gash, "Technological frames: making sense of information technology in organizations," $A C M$ Transactions on Information Systems (TOIS), Vol. 12, 1994, pp. 174-207.

[35] P. M. Leonardi, "Theoretical foundations for the study of sociomateriality," Information and Organization, Vol. 23, 2013, pp. $59-76$.

[36] W. J. Orlikowski, "Using technology and constituting structures: A practice lens for studying technology in organizations," Organization Science, Vol. 11, 2000, pp. 404428.

[37] K. K. Cetina, T. R. Schatzki, and E. Von Savigny, The practice turn in contemporary theory, Routledge, 2005.

[38] M. Barrett and E. Davidson, "Exploring the diversity of service worlds in the service economy," in Information Technology in the Service Economy: Challenges and Possibilities for the 21 st century, Eds. M. Barrett et al., Springer, 2008, pp. 1-10.

[39] OECD, "Measuring well-being and progress. Retrieved 7 August 2017 from: http://www.oecd.org/std/Measuring WellBeing and Progress Brochure.pdf, 2013.

[40] SOU, "Se medborgarna - för bättre offentlig service SOU 2009:92," Utveckling av lokal service i samverkan Stockholm, 2009:92.

[41] A. J. Meijer, "Networked coproduction of public services in virtual communities: From a government-centric to a community approach to public service support," Public Administration Review, Vol. 71, 2011, pp. 598-607.

[42] B. O. Rothstein and J. A. Teorell, "What is quality of government? A theory of impartial government institutions," Governance, Vol. 21, 2008, pp. 165-190.

[43] J. W. Treem and P. M. Leonardi, "Social media use in organizations: Exploring the affordances of visibility, editability, persistence, and association," Annals of the International Communication Association, Vol. 36, 2013, pp. 143-189.

[44] B. Eaton, S. Elaluf-Calderwood, C. Sorensen, and Y. Yoo, "Distributed tuning of boundary resources: the case of Apple's iOS service system," Mis Quarterly, Vol. 39, 2015, pp. 217-243.

[45] C. O'Neil, "The Era of Blind Faith in Big Data Must End," Retrieved from: https://en.tiny.ted.com/talks/cathy_o_neil_the_era_of_blind_fait $\mathrm{h}$ _in_big_data_must_end, 2017.

[46] R. K. Yin, Case study research: Design and methods: Sage Publications, 2013

[47] G. Walsham, "Interpretive case studies in IS research: nature and method," European Journal of Information Systems, Vol. 4, 1995, pp. 74-81.

[48] V. Venkatesh, S. A. Brown, and H. Bala, "Bridging the qualitative-quantitative divide: Guidelines for conducting mixed methods research in information systems," MIS Quarterly, Vol. 37, 2013.

[49] SALAR, "E-förvaltning och e-tjänster i Sveriges kommuner 2011." Accessed 2015-03-30 at: http://webbutik.skl.se/sv/artiklar/e-forvaltning-och-e-tjanster-isveriges-kommuner-2011.html [The Swedish Association of Municipalities and Regions], 2011.

[50] P. Davidsson and A. Thoresson, "Svenskarna och internet 2017: Undersökning om svenskarnas internetvanor. IIS," Internetstiftelsen i Sverige, 2017.

[51] Smampion, “Årsrapport - Sveriges kommuner på Facebook," 2016. 